\title{
A Benefit-Maximization Solution to Our Faculty Promotion and Tenure Process
}

\author{
Somjit Barat (Corresponding author) \\ Faculty of Business, Pennsylvania State University \\ 1 Campus Drive, Mont Alto, PA 17237, USA \\ Tel: 1-717-749-6207Ｅ-mail: sub26@psu.edu
}

\begin{abstract}
Hanafiah Harvey
Faculty of Business and Economics, Pennsylvania State University

1 Campus Drive, Mont Alto, PA 17237, USA
\end{abstract}

Tel: 1-717-749-6027Ｅ-mail: hhh10@psu.edu

Received: June 4, 2015 Accepted: July 28, 2015 Published: August 5, 2015

doi:10.5296/jei.v1i2.7747ＵRL: http://dx.doi.org/10.5296/jei.v1i2.7747

\begin{abstract}
Tenure-track/tenured faculty at higher education institutions are expected to teach, conduct research and provide service as part of their promotion and tenure process, the relative importance of each component varying with the position and/or the university. However, based on the author's personal experience, feedback received from several colleagues, and review of research on this topic, the authors note that there is considerable concern among many faculty members as to what constitutes an optimal mix of the critical components of evaluation.

Consequently, the authors present a cost-benefit utilitarian model using which, the faculty member can objectively allocate his/her limited resources, such as time commitment and effort, between teaching and research activities. The authors believe that such a blueprint will prove to be a critical tool for the tenure-track candidate, as well as for the university administration. One of the notable features of the proscribed tool is that it is not discipline-specific and therefore, has a wide application in university governance.
\end{abstract}

Keywords: Tenure, Promotion, Administration, Peer-review, Teaching, Research 


\section{Al Macrothink}

\section{Introduction}

Tenure-track and tenured faculty at higher education institutions are expected to perform teaching, research and service as part of their promotion and tenure (P\&T) process, the relative importance of each component being dependent on the position of the faculty and/or the university. However, based on feedback received from several colleagues at higher education institutions, their personal experiences and review of extant literature, the authors note that there is considerable concern (if not confusion) among many tenure-track faculty members as to what should be the optimal mix of the different components of evaluation. This may be either due to lack of clearly defined P\&T requirements at the incumbent's institution, or misinterpretation of word of mouth P\&T guidelines.

The biggest concern seems to be the dichotomy between (the weightage assigned to) research and teaching at different institutions. Below are the results (in \%) of a faculty survey (conducted by Carnegie Foundation's National Surveys of Faculty) during which the respondents were asked the same question in 1969 and in 1989: "In my department, is it difficult for a faculty to achieve tenure if he or she doesn't publish"?

Table 1. Faculty responses in \%

\begin{tabular}{|l|l|l|}
\hline Criteria & $\mathbf{1 9 6 9}$ & $\mathbf{1 9 8 9}$ \\
\hline Overall agreed & 21 & 42 \\
\hline Faculty at PhD-granting departments & 27 & 71 \\
\hline Liberal arts colleges & 6 & 24 \\
\hline Comprehensive institutions & 6 & 43 \\
\hline
\end{tabular}

Such startling change in attitude towards the role of scholarship in faculty evaluation is further corroborated by figures from another study of the 1988 National Survey of Postsecondary Faculty according to which, more teaching led to lower pay while more time spent on research resulted in better quality publications and as a corollary, led to higher pay (Fairweather, 1993).

\section{Sources of Confusion}

Sources of confusion with regard to P\&T (and relevant comments from a survey on faculty perception of P\&T procedure conducted by Blyler et al. in 1997) are provided to buttresses the authors' views: 


\subsection{Weight of Publications}

As referred to in the table, significant changes in weight of publications have taken place over the last several decades. Overall, while the importance of scholarly work has assumed significance, the variety of such contributions has increased more than ever before. For example, a peer-reviewed journal acceptance does not necessarily command the same 'value' as a book review. Consequently, this has only contributed to the confusion in the already volatile P\&T decision-making process. Consider the following comments from faculty:

There was some discussion about whether or not my research was 'pedagogical publications' vs. research or scholarship, but I managed to win that argument because my research was considered 'theoretical' enough. People doing classroom or teacher research (or workplace studies) could not have counted that as research/scholarship at that time.

I would like to note that business schools don't think much of book chapters. I have to fight constantly to get them to 'count' book chapters; they tend to believe that only journal articles are truly refereed. They won't count book chapters as equivalent-no matter how insignificant the journal. This is clearly a disciplinary distinction separating the humanities and social sciences, I would think.

\subsection{Discontent among Faculty}

Even though scholarly publications have gained importance over the years, a sizable section of faculty feel disenchanted with and is concerned about the lack of respect towards the 'teaching' component of faculty evaluation (Lovett, 1993).

For example, one extensive faculty survey suggests that $68 \%$ of faculty across the board and as high as $77 \%$ of faculty in $\mathrm{PhD}$-granting institutions prefer some indicator other than just research productivity to account for a faculty member's capability to achieve tenure (Boyer, 1990). Furthermore, a notable percentage of faculty - especially the junior ones, strongly prefers more emphasis on teaching instead of on research for P\&T decisions. At a minimum, the respondents called for a more thorough evaluation of publication quality (Jarvis, 1991). According to the Chronicle of Higher Education, lawmakers were shocked that the average professor spends only nine hours in the classroom (Cage, 1995). What adds to the perplexity (and therefore, confusion) to this situation that faculty at two-year colleges (are expected to) spend 40 hours or more in class whereas their counterparts at four-year institutions easily get by with 10 hours or less, according to a 1990 National Center of Education Statistics report. This is reflected in the following comments:

At all three institutions, [teaching] has played only a disqualifying role, although at my current one the standards are higher, so you have to be a good teacher not to be disqualified, whereas at previous institutions you only had to be not-awful.

Bad teaching can get you fired if you don't publish enough; good teaching won't get you retained if you don't publish enough; service is used as an excuse to fire someone if the service record is slight and the committee needs such an excuse. Teaching in itself never plays much of a role; An exemplary teaching record would buoy a marginal publication 
record, extending a bit what would be acceptable. But publication remains the yardstick for all decisions. Service in itself never plays a role worth mentioning.

\subsection{Broadening View of Scholarly Activities}

A third source of confusion which directly follows from the second point, is the wider array of activities that have recently come under the umbrella of research at some institutions e.g. book chapters, book reviews, books, magazine contributions and the like (Gebhardt \& Barbara, 1997). However, it is not at all clear how much weight each component will carry. Thus, it places a bigger burden on the review committee to judge the performance of the candidate.

Moreover, there can be potential confusion about the relationship between scholarly activities and teaching (Platter, 1995), mission of the tenure-granting institution (both the authors happen to be from an institution with a land-grant mission) and between scholarly work and social expectations (Levine, 1993).

\subsection{Dichotomy between Teaching- and Research-Oriented Institutions}

Even though these are the broad classifications for most higher education institutions, the relative importance of each component is a source of confusion when it comes to P\&T decisions. For example, most institutions have an arbitrary rule of thumb along the following lines: $40 \%$ weight on teaching, $50 \%$ on research and $10 \%$ on services or variations of this. Moreover, the role of consulting in the decision-making process is not succinct either, especially for social sciences and humanities. There are multiple problems associated with this ideology. First, the institution does not, as a matter of rule, provide these guidelines in writing.

This brings up the second, and even more serious problem: not only does such practice leave considerable scope for misinterpretation by the faculty member and/or the existing review committee, but also the institute itself often changes its 'positioning goal' (e.g. become research-oriented from a traditional teaching-oriented institute). And even as all this happens while the faculty member is still on the tenure- track, such higher level decisions are either not relayed formally to the incumbent faculty member or it is relayed too late.

Finally, it is also not uncommon where a newly-hired head decides to steer the institution in a different direction, and all existing rules (as vague as they are) are altered, once again putting the tenure-track member in jeopardy, as amply voiced by the following faculty members:

Consulting is like working at 7-11: It gets you money but no credit towards tenure/promotion. Now if you do your consulting in such a way that it generates new knowledge that you can turn into publications, that's something different; if you consult on a unique or significant problem, the products of that work should be there to show. But the main thing is generating refereed publications. Consulting itself has no value.

I've been warned that I have to "do everything"- be available on campus, have good evaluations from students, participate in additional committees, teach more courses-if I'm going to be allowed to continue participating on the board of professional societies, 
publishing papers and books, attending and making presentations at conferences, and working as a consultant. So far I've been able to do it all, but I often find I'm working 90-hour weeks.

\subsection{Lack of Knowledgeable Committee Members}

This problem is especially acute in smaller campuses. In such situations, the institution has to 'work' with available reviewers who do not necessarily understand the candidate's work and/or unable to appreciate the depth/contribution of his/her pedagogy. The problem is exacerbated when the candidate's research either spans several disciplines or has undergone a shift of focus. Alternatively, the institution is forced to look outside for feedback, which makes the decision process more complex, lengthy and arguably, fraught with unfair evaluation of the candidate's application.

In addition, quite naturally, as the faculty member attains seniority, he/she gets more and more 'specialized' and the quality of research also assumes more significance. Consequently, finding a reviewer who is at least as much as (if not more) qualified becomes challenging, which becomes apparent in the following comments:

The administration was not the problem - the faculty of the business school was. They had a great deal of trouble, even though I changed fields to do work that I thought would be valued more highly by them. In general, the faculty rejected management communication, business communication, communication, English, etc., as fields in which I could get tenure. Thus my research and its methodology had to stand up to reviewers from other disciplines recognized by the business school...

It's often more difficult because we want TEN letters-five from people suggested by the candidate and five to be anonymous, chosen by the department. In the first place, when coming up for full professor, there are probably no more than two dozen (if that) full professors of technical communication out there to choose from.

In the light of the above discussion, we argue that there exist several perspectives on challenges that newly hired faculty encounter in their career. Tierney and Rhoades (1993) note, for example, that the initial years are fraught with feelings of loneliness, disillusionment and adjustment, lack of intellectual stimulation and collegiality, inability to muster the local 'culture', time and other constraints.

To buttress their point, the authors further cite an instance of a faculty member who received a job offer on the phone, but no further details as to what was expected of her. Even after she accepted the offer, she had no clear indication of the requirements and publication/service expectations, including the classic 'quality vs quantity' issue. This faculty member was never provided any clear guidelines... all that she received were input from the secretary and hearsay from colleagues... which, unfortunately, is not that unique in an academic environment.

It is no wonder, therefore, that several authors have cited the role of controllable and uncontrollable factors that enter into the faculty P\&T decision process, such as misuse of 
student evaluations, peer observations, teaching portfolios, using student evaluation data to improve teaching performance and for administrative decisions etc. (Seldin, 2006).

What makes this process of evaluating faculty even more challenging is that, the standards, expectations and procedures are evolving, especially flexible expectations and changing roles and responsibilities. For example, traditionally, the faculty was primarily expected to teach and conduct some minimal amount of research. But now many universities expect their faculty members to play a substantive role in community relations, business development and program enhancement. Ironically, not all of these are properly relayed to the incumbent. Consequently, clarifying expectations from faculty members and the consequent use of evaluative data have assumed an important role in the tenure decision process (Paulsen, 2002).

Arreola (2000) goes even one step further to suggest that we should consider the source of information, the weight given to different sources, and how information should be gathered, in addition to other dimensions of evaluation.

Relevant research literature suggests that policy makers have grappled with and attempted to tackle the lack of clear P\&T guidelines for quite some time. While Hopkins (1974) prescribes a mathematical model that can be used to vary retirement age, and extend service time for tenure and non-tenured faculty, Saaty and Ramanujam (1983) suggest a hierarchical solution.

Despite such concern over the P\&T process, it is ironic that research in this field has gained momentum not long ago, very few of which actually offer any concrete suggestion for an better-articulated P\&T process (Rude, 1995; Harris, 1995; Killingsworth, 1995).

Tierney (1998), on the other hand, discusses several perspectives on productivity and P\&T guidelines. Such attempts have been mostly academic, which pose operational challenges. At the same time, lack of clear direction and P\&T guidelines and prevalence of an antiquated system are quite predominant, irrespective of the size and reputation of the institution. Hence, there is undoubtedly a need to address this problem.

Consequently, the authors present a cost-benefit utilitarian model based on an indifference-curve analysis (Pindyck \& Rubinfeld, 2010) commonly used in microeconomic theory. The fundamental premise of our model is that, the faculty member's resources (time commitment, effort) are limited. Therefore, the goal is to allocate such scarce resources between the most demanding components of P\&T activities: teaching, research and services.

We simplify our model to allocate faculty time/resource constraints between only teaching and research, since these are typically the most important components of tenure requirements at most major universities.

Basing our proposition on rational choice theory (Jevons, 1862), we argue that the faculty member follows a Cobb-Douglas utility-maximization model (Figure 1) to maximize his/her 'returns' on tenure activities (ROTA) subject to effort (time) constraint (which is typically limited to 40 hours/week).

The faculty member can derive optimal level of tenure credits based on the most 'rational' 


\section{Macrothink}

combination of teaching and research loads. In other words, the suggested model helps the faculty member enjoy the highest ROTA under the time and resource constraints.

\section{The Model}

Following microeconomic theory, we assume that faculty members follow two basic properties of rational choice: a) Completeness: The faculty member's behavior can be categorized in an order of preference. In any situation, faculty may prefer research (R) to teaching ( $\mathrm{T}), \mathrm{T}$ to $\mathrm{R}$ or consider $\mathrm{T}$ and $\mathrm{R}$ as equally attractive. As such, the faculty member understands and can always decide between the two alternatives and (b) Non-satiation: more of at least $\mathrm{T}$ or $\mathrm{R}$ is better than less of either.

\subsection{Credit Indifference Curve (CIC)}

The goal of the faculty member is to allocate limited resources between the two most common components of P\&T activities: teaching and research (Note 1). The outline of our model is as follows: Based on Figure 1, Teaching ( $\mathrm{T}$ ) is measured along the Y-axis and Research (R) along the X-axis. The CIC (credit indifference curve) represents the loci of choices between $\mathrm{T}$ and $\mathrm{R}$ that yield the same level of ROTA for the faculty member. As such, the faculty member is free to choose (and derives the same level of ROTA on) any point on the CIC.

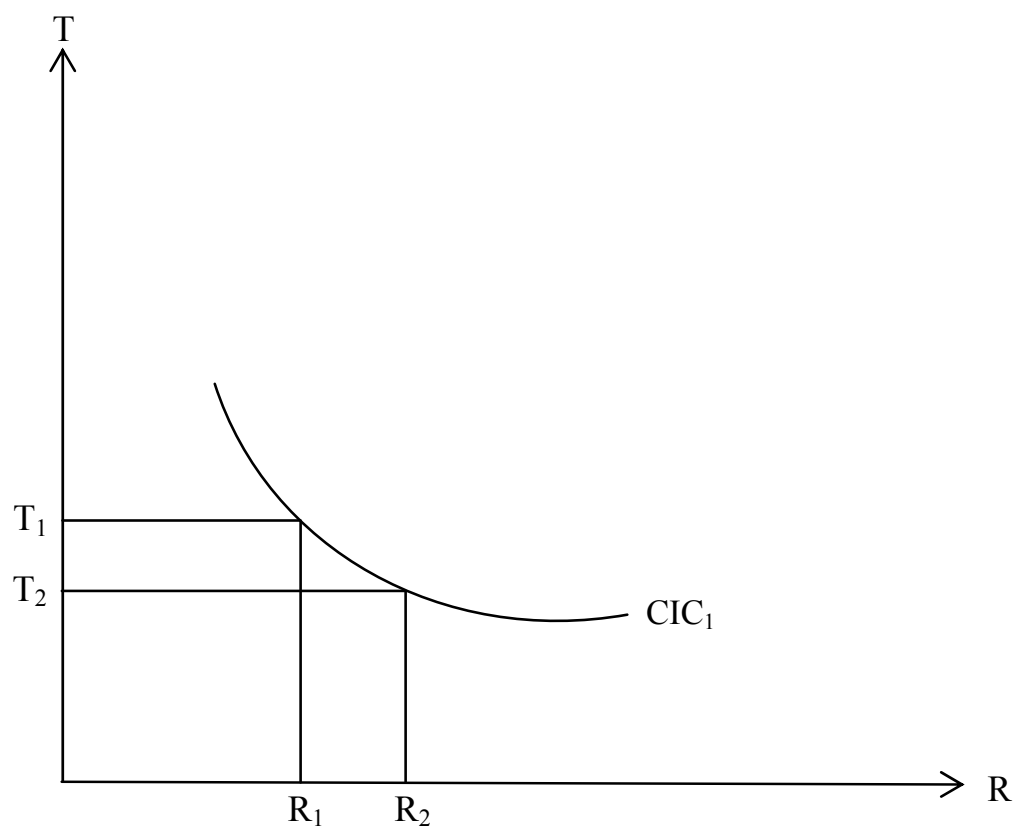

Figure 1. Marginal rate of substitution (MRS)

The negative slope of the CIC (known as the marginal rate of substitution (MRS)) (Note 2) represents the number of units of $\mathrm{T}$ a faculty member is willing to forgo in return for an extra unit of $\mathrm{R}$, while maintaining the same level of ROTA. As such, a faculty member is willing to give up $\left(T_{2}-T_{1}\right)$ units of $T$ to receive $\left(R_{2}-R_{1}\right)$ more of units of $R$ and this trade will leave the 


\section{Macrothink}

faculty neither better nor worse off in terms of ROTA.

\subsection{Effort Constraint Line (ECL)}

As reflected by the Effort Constraint Line ECL in Figure 2, faculty's effort is constrained by time (Note 3). Figure 3 shows the effect of change in available time on ECL (Note 4), with F representing the original ECL and G representing ECL with an increase in time spent on both $\mathrm{T}$ and R. Conversely, a reduction in allocation of time lowers the intercept of ECL to E.

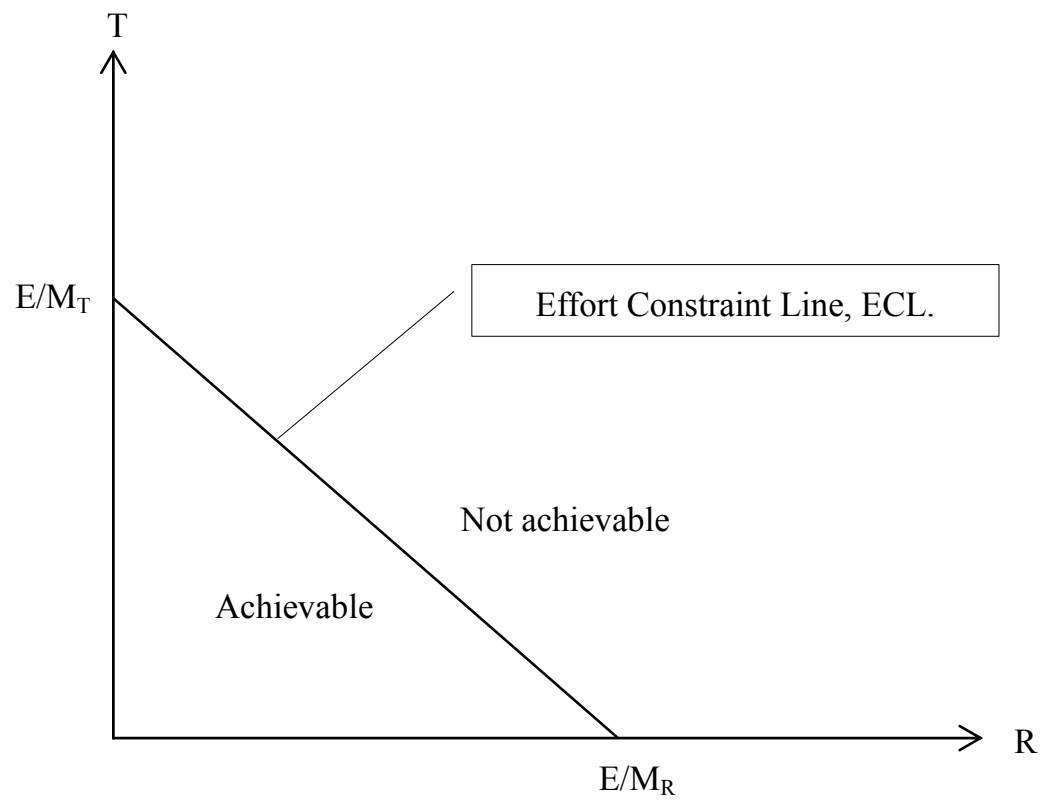

Figure 2. Effort constraint line (ECL)

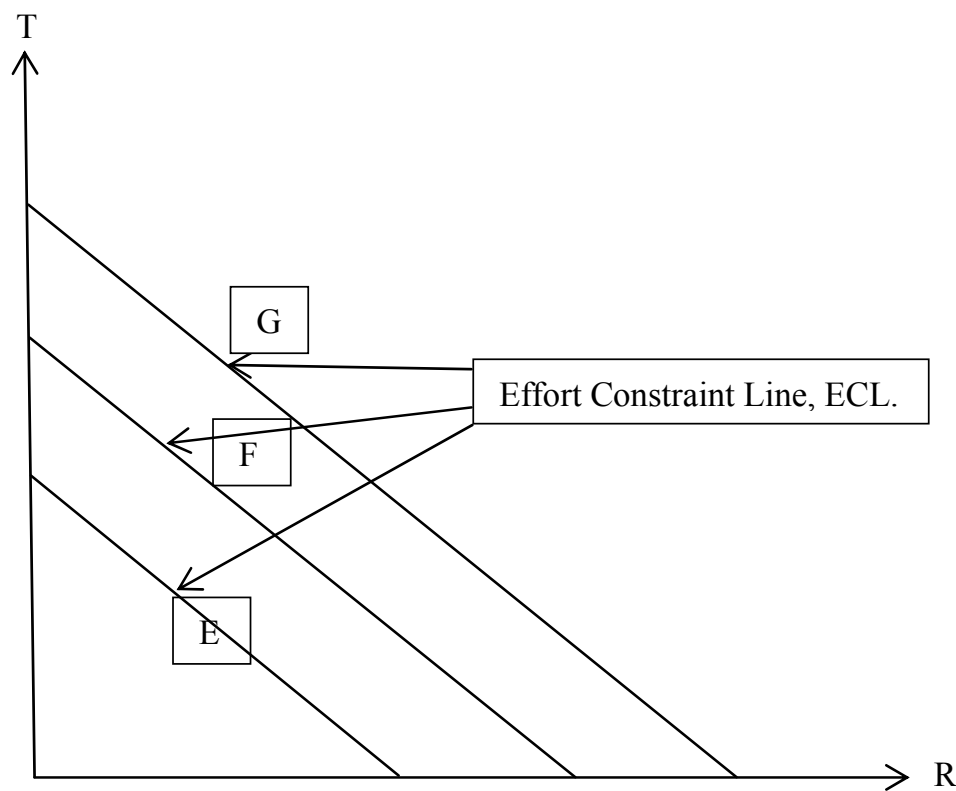

Figure 3. Movement of ECL based on available resources 


\section{Macrothink}

The ECL shows the maximum possible time (resource) a faculty member can allocate for $\mathrm{T}$ or R. The slope of ECL is equal to $-\mathrm{M}_{\mathrm{R}} / \mathrm{M}_{\mathrm{T}}$ (Note 5). A faculty member can expend effort (and earn corresponding tenure credits) either entirely on $\mathrm{T}$ or entirely on $\mathrm{R}$, or on a combination. From Figure 4, assuming $B$ is the original ECL, an increase of $M_{R}$ increases the absolute value of the slope of ECL (ECL shift from B to A); a decrease of $\mathrm{M}_{\mathrm{R}}$ decreases the absolute value of the slope of ECL (ECL shift from B to C).

Next, referring to Figure 5, the authors propose that a faculty member derives optimal tenure credits by maximizing ROTA (which is a function of $\mathrm{T}$ and $\mathrm{R}$ ) subject to the time constraint. Equilibrium (i.e. optimal allocation of effort between $\mathrm{T}$ and $\mathrm{R}$ ) occurs at $\mathrm{M}^{*}$ (intersection of CIC with ECL) corresponding to which, faculty performs $\mathrm{T}^{*}$ units of teaching and $\mathrm{R}^{*}$ units of research towards fulfillment of Return on Tenure Activities (Note 6).

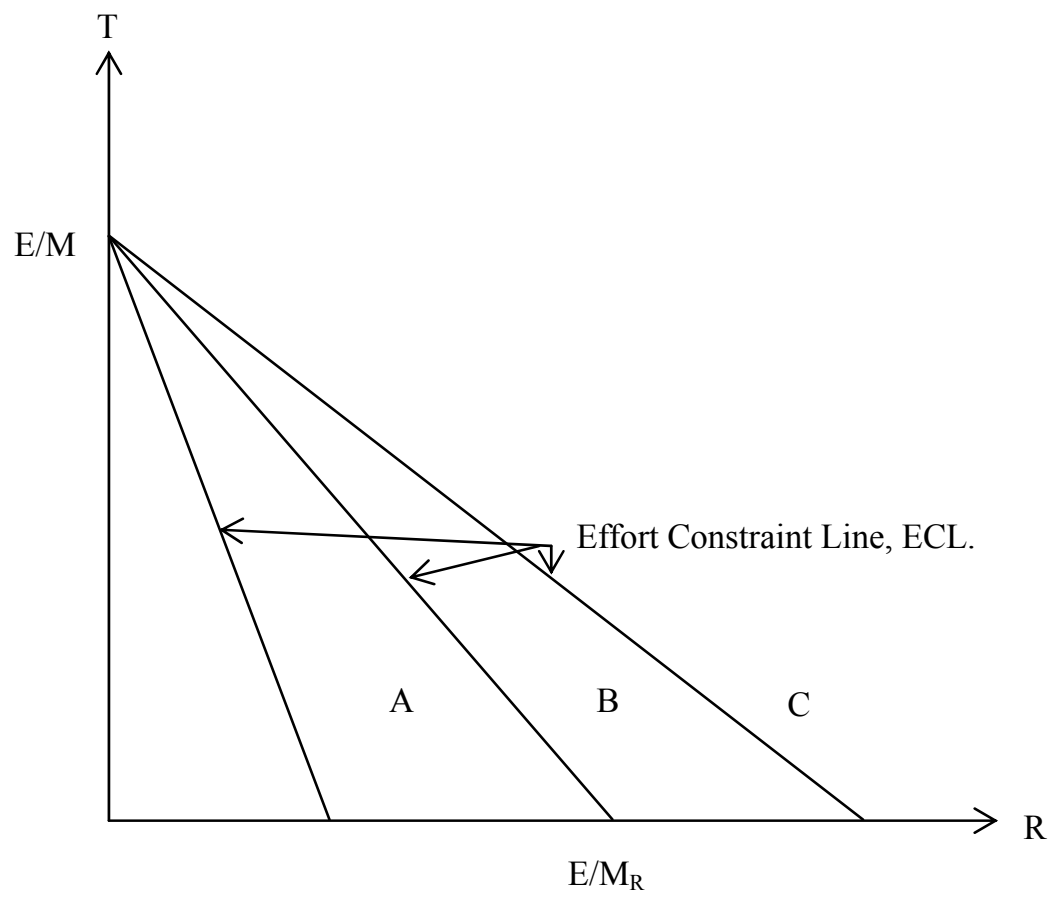

Figure 4. Change of slope of ECL 


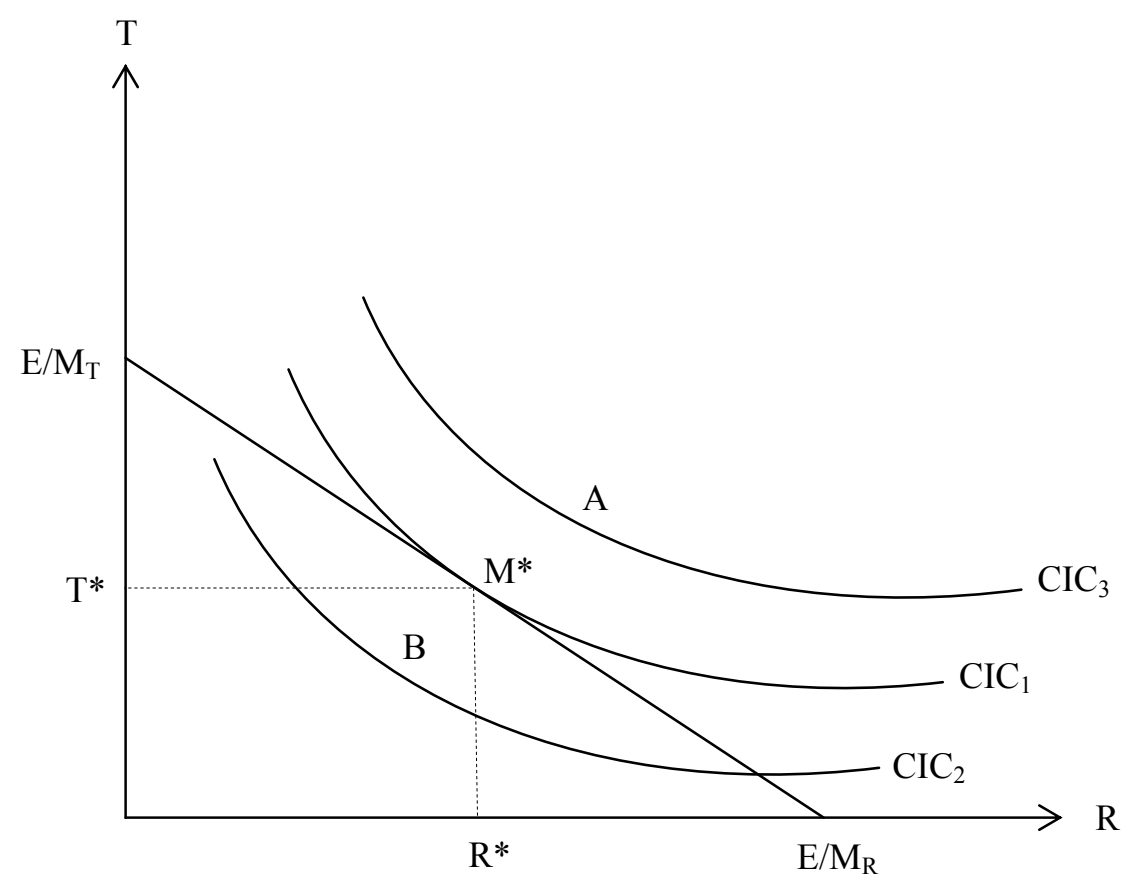

Figure 5. Maximizing return on tenure activities (ROTA)

\section{Research Limitations/Implications}

We have not included services as part of our model. However, this decision is based on our understanding that typically it plays a subordinate role in most P\&T decisions especially when compared to teaching and research.

Secondly, the model assumes that the faculty member is able to measure how much time he/she needs to devote to teaching and research in order to receive an 'unit' of return. While this requires meticulous record-keeping, it is an important component of the dossier that many universities already require their faculty members to maintain as part of their P\&T review packet. Therefore, the administration can utilize this information to 'create' the faculty member's credit indifference curve and effort constraint line.

Third, the credit indifference curve and effort constraint line might change the intercept(s) and/or slope if the faculty member decides to vary the time allocated to research or teaching, which, once again, requires thorough record-keeping.

In order to be truly effective, we need to convince the university administration to adopt this model or at least consider some changes along these lines, which may be a challenge given the archaic nature of some institutions.

Despite the above limitations, to the best of the authors' knowledge, this approach is a unique attempt to apply the rational choice theory to faculty P\&T guidelines. Specifically, at present, many tenure-track faculty members get stressed out having to deal with the uncertainty and confusion of P\&T guidelines and expectations. This is counterproductive from both the 
administration and the faculty's standpoints. The current model fills the gap for a tool using which, faculty can measure and optimally allocate their resources between the two most important components of P\&T i.e. teaching and research.

As a result, the faculty member can devote more time towards teaching and research activities and worry less on whether he/she is on track for P\&T. Consequently, universities can attract more qualified tenure-track faculty, who can presumably become more productive and objective during their tenure years. If properly executed, eventually such a framework can lead to more faculty members getting tenured, thereby improving the overall quality of pedagogy at centers of higher education.

Finally, the university administrator can use this tool to more objectively evaluate the faculty member's standing when it comes to granting tenure to him/her. Thus, there is more transparency in the P\&T system, and less vulnerability on the part of the faculty member.

\section{Conclusion}

While we do not expect to eliminate the uncertainty and confusion associated with the P\&T process with our proposed model, we strive our best to at least encourage policy makers to think more objectively. The goal is to operationalize the P\&T process as best as we can. The current fragility of the system is amply captured in the following comments of a seasoned P\&T committee member:

"The fact remains that, despite the best efforts of schools and professional organizations to establish and enforce uniform, objective standards for tenure and promotion, departments and institutions still have the flexibility, borne of criteria that are variable of necessity, to retain and promote the people they want to keep and to wash out the rest. To rephrase a signal idea from Alice in Wonderland (italics original), my guess is that in most reviews for tenure and promotion, the verdict is reached first, implicitly, and the justification is adduced afterward, when the evidence is formally examined..." (Bloom, 1997).

\section{References}

Arreola, R. A. (2000). Developing a Comprehensive Faculty Evaluation System: A Handbook For College Faculty And Administrators On Designing And Operating A Comprehensive Faculty Evaluation System. Anker Publishing Company, Inc.

Bloom, L. Z. (1997). The Importance of External Reviews in Composition Studies. In C. G. Richard \& G. S. G. Barbara (Eds.), Academic Advancement in Communication Studies: Scholarship, Publication, Promotion, Tenure (pp. 167-177). Lawrence Erlbaum Associates, Publishers, Mahwah, New Jersey.

Blyler, N. R., Margaret, B. G., \& Charlotte, T. (1997). Scholarship, Tenure, and Promotion in Professional Communication. In C. G. Richard \& G. S. G. Barbara (Eds.), Academic Advancement in Communication Studies: Scholarship, Publication, Promotion, Tenure (pp. 71-87). Lawrence Erlbaum Associates, Publishers, Mahwah, New Jersey.

Boyer, E. (1990). Scholarship Reconsidered: Priorities of the Professorate. Princeton: 


\section{Macrothink}

Carnegie Foundation for the Advancement of Teaching.

Cage, M. C. (1995). Regulating Faculty Workloads. Chronicle of Higher Education, 41(19), A30.

Fairweather, J. S. (1993). The Nature of Tradeoffs. Change, Jul./Aug., 44-47.

Gebhardt, R. C., \& Barbara, G. S. G. (1997). Academic Advancement in Composition Studies: Scholarship, Publication, Promotion, Tenure. Lawrence Erlbaum Associates, Publisher, Mahwah, New Jersey.

Harris, J. S. (1995). Getting Promoted, Issues in Promotion and Tenure for Faculty in Technical Communication: Guidelines and Perspectives. N.p.: Association of Teachers and Technical Writing, edited by Elizabeth Tebeaux.

Hopkins, D. S. P. (1974). Analysis of Faculty Appointment, Promotion, and Retirement Policies. Higher Education, 3(4), 397-418. http://dx.doi.org/10.1007/BF00153950

Jarvis, D. K. (1991). Junior faculty Development: A handbook. New York.

Jevons, W. S. (1862). A General Mathematical Theory of Political Economy.

Killingsworth, J. M. (1995). What Counts as Quality in Publication Record? In E. Tebeaux (Ed.), Issues in Promotion and Tenure for Faculty in Technical Communication: Guidelines and Perspectives, N.p.: Association of Teachers and Technical Writing.

Levine, G. (1993). The Real Trouble. Profession 93, New York.

Lovett, C. M. (1993). Listening to the Faculty Grapevine. AAHE Bulletin, 46, 3.

Mansfield, E., \& Yohe, G. (2000). Microeconomics (10th ed.). W. W. Norton.

National Center for Education Statistics. (1990). Faculty in Higher Education Institutions, 1988. Contractor Report. Data Series DR-NSOPF-87/88-1.27. Washington: US Department of Education.

Nicholson, W. (1998). Microeconomics Theory: basic principles and extension (7th ed.). Dryden Press.

Paulsen, M. B. (2002). New Directions for Institutional Research (No. 114). Wiley Periodicals, Inc.

Pindyck, R. S., \& Daniel, L. R. (2010). Microeconomics. Prentice Hall.

Platter, W. (1995). Future Work: Faculty Time in the $21^{\text {st }}$ Century. Change, May/June. http://dx.doi.org/10.1080/00091383.1995.10544660

Rude, C. (1995). Standards versus Standardization: Constructing Criteria for Tenure and Promotion in Technical Communication. In E. Tebeaux (Ed.), Issues in Promotion and Tenure for Faculty in Technical Communication: Guidelines and Perspectives. N.p.: Association of Teachers and Technical Writing. 
Saaty, T. L., \& Vasudevan, R. (1983). An Objective Approach To Faculty Promotion And Tenure By The Analytic Hierarchy Process. Research in Higher Education, 18(3), 311-31. http://dx.doi.org/10.1007/BF00979603

Seldin, P. (2006). Changing Practices in Evaluating Teaching: A Practical Guide To Improved Faculty Performance And Promotion/Tenure Decisions (Vol. 10). Jossey-Bass.

Tierney, W. G. (1998). The Responsive University: Restructuring for High Performanc. Baltimore: The Johns Hopkins University Press.

Tierney, W. G., \& Rhoads, R. A. (1993). Enhancing Promotion, Tenure and Beyond: Faculty Socialization as a Cultural Process. ASHE-ERIC Higher Education Report No. 6. ASHE-ERIC Higher Education Reports.

\section{Appendix}

Appendix 1.

We assume that a faculty has the option to choose a combination of teaching $(\mathrm{T})$ and research (R) with a given time constraint. As such, we present the equations as follows:

$$
\mathrm{M}_{\mathrm{R}} \mathrm{R}+\mathrm{M}_{\mathrm{T}} \mathrm{T}=\mathrm{E}
$$

Equation (1) represents the Effort Constraint Line, ECL.

$M_{T}$ is the number of $T$ 'credit units' while $M_{R}$ is the number of $R$ 'credit units' the faculty member receives. $\mathrm{E}$ is maximum number of hours allowed to spend on $\mathrm{R}$ and/or on $\mathrm{T}$. If a faculty spent all his/her time on $\mathrm{R}$, he/she will produce $\mathrm{E} / \mathrm{M}_{\mathrm{R}}$ credit units of $\mathrm{R}$. Likewise, if all effort is utilized on $\mathrm{T}$, he/she will produce $\mathrm{E} / \mathrm{M}_{\mathrm{T}}$ credit units of $\mathrm{T}$. Thus, if the time spent on $\mathrm{T}$ is 1 hour and the time spent on $R$ is 2 hours and a faculty has 40 hours, then $M_{T}+2 M_{R}=40$.

It is possible to plot the combination of $\mathrm{T}$ and $\mathrm{R}$ that a faculty can spend on the same graph as the CIC credit indifference curve (Refer to Figure 1). Solving Equation (1),

$$
T=\frac{E}{M_{T}}-\frac{M_{R}}{M_{T}} R
$$

The first term on the right hand side is the intercept of the line on the vertical axis. It is the amount of $\mathrm{T}$ that can be spent by a faculty if he or she utilized all his time on $\mathrm{T}$. The slope of the line is the ratio of $\left(-\mathrm{M}_{\mathrm{R}} / \mathrm{M}_{\mathrm{T}}\right)$.

Appendix 2.

We assume that the ROTA follows a Cobb- Douglas production function given as follows:

$$
\operatorname{ROTA}(R, T)=R^{\alpha} T^{\beta}, \text { where } \alpha+\beta=1(\text { Note } 7)
$$


Subject to a time constraint (Note 8),

$$
\mathrm{E}=\mathrm{M}_{\mathrm{R}} \mathrm{R}+\mathrm{M}_{\mathrm{T}} \mathrm{T}
$$

We can solve ROTA maximizing values of $R$ and $T$ for any time $\left(M_{R}, M_{T}\right)$ and $E$ is the maximum number of hours.

Using the Lagrangian expression,

$$
L=R^{\alpha} T^{\beta}+\lambda\left(E-M_{R} R-M_{T} T\right)
$$

yields the first order conditions:

$$
\begin{aligned}
& \frac{\partial L}{\partial R}=\alpha R^{\alpha-1} T^{\beta}-\lambda M_{R}=0 \\
& \frac{\partial L}{\partial T}=\beta R^{\alpha} T^{\beta-1}-\lambda M_{T}=0 \\
& \frac{\partial L}{\partial \lambda}=E-M_{R}-M_{K}=0
\end{aligned}
$$

Taking the ratios of the first two terms shows that,

$$
\frac{\alpha T}{\beta R}=\frac{M_{R}}{M_{T}}
$$

or,

$$
M_{T} T=M_{R} R\left(\frac{1-\alpha}{\alpha}\right)
$$

Substituting the first order condition in Equation (6) into the time constraint (2) yields,

$$
E=M_{R} R-M_{T} T=M_{R} R+M_{R} R\left(\frac{1-\alpha}{\alpha}\right)=M_{R} R\left(1+\frac{1-\alpha}{\alpha}\right)=M_{R} R \frac{1}{\alpha}
$$

Solving for R yields,

$$
R^{*}=\frac{E \alpha}{M_{R}}
$$

Solving for T yields,

$$
T^{*}=\frac{E \beta}{M_{T}}
$$




\section{IIMacrothink}

Results show that given Equation (1) as our ROTA function, a faculty will always choose to allocate $\alpha$ percent of a his/her effort to spend on $\mathrm{R}$ (i.e. $\mathrm{M}_{\mathrm{R}} \mathrm{R} / \mathrm{E}=\alpha$ ) and $\beta$ percent to acquire $\mathrm{T}\left(\mathrm{M}_{\mathrm{T}} \mathrm{T} / \mathrm{E}=\beta\right)$.

\section{Notes}

Note 1. Recognizing that service typically weighs less than teaching or research, we decided to exclude it from our model.

Note 2. The model is based on the assumption that the MRS of T for R will fall as the faculty member accumulates more of R, leading to a convex CIC that lies above its tangent as seen in Figure 5. In addition, a faculty member is considered 'irrational' for choosing point $\mathrm{B}$ because he/she can achieve a higher level of productivity, $\mathrm{CIC}_{1}$. On the other hand, point $\mathrm{A}$ on $\mathrm{CIC}_{3}$ is not achievable since the faculty member does not have sufficient resources.

Note 3 . We assume that a faculty has a maximum of 40 hours/week.

Note 4. Based on equation (2) from Appendix 1, an increase in time constraint shifts the ECL outward while leaving its slope unchanged.

Note 5. Refer to Appendix 1.

Note 6. Refer to Appendix 2 for mathematical approach to equilibrium using Lagrangian Multiplier.

Note 7. $\beta=1-\alpha$

Note 8 . The time constraint is presented as equality because of the assumption of no satiation i.e. a faculty will spend all his available time.

\section{Copyright Disclaimer}

Copyright for this article is retained by the author(s), with first publication rights granted to the journal.

This is an open-access article distributed under the terms and conditions of the Creative Commons Attribution license (http://creativecommons.org/licenses/by/3.0/). 